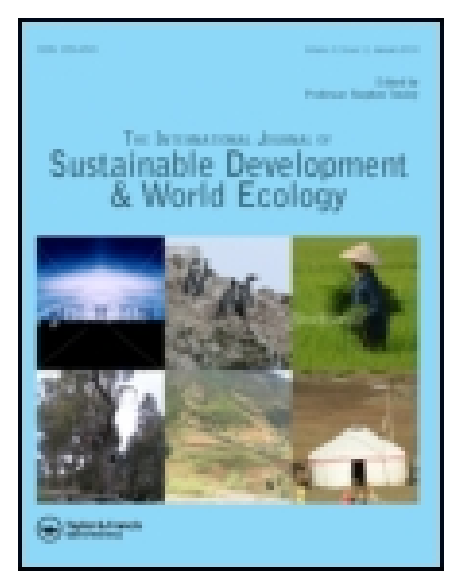

International J ournal of Sustainable Development \& World Ecology

Publication details, including instructions for authors and subscription information:

http://www. tandfonline.com/loi/tsdw20

\title{
Designing a framework for dynamic monitoring of ecosystem changes in the Lugu Lake
} region

Hongbing Deng , Shaobo Chen \& Rencai Dong

Published online: 20 Sep 2010.

To cite this article: Hongbing Deng, Shaobo Chen \& Rencai Dong (2008) Designing a framework for dynamic monitoring of ecosystem changes in the Lugu Lake region, International J ournal of Sustainable Development \& World Ecology, 15:1, 56-61, DOI: 10.1080/ 13504500809469769

To link to this article: http:// dx.doi.org/ 10.1080/13504500809469769

\section{PLEASE SCROLL DOWN FOR ARTICLE}

Taylor \& Francis makes every effort to ensure the accuracy of all the information (the "Content") contained in the publications on our platform. However, Taylor \& Francis, our agents, and our licensors make no representations or warranties whatsoever as to the accuracy, completeness, or suitability for any

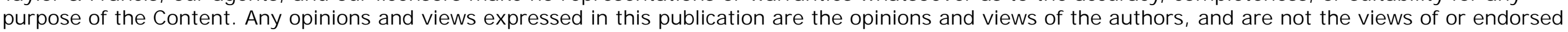

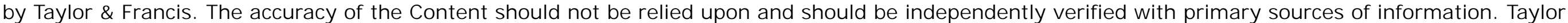

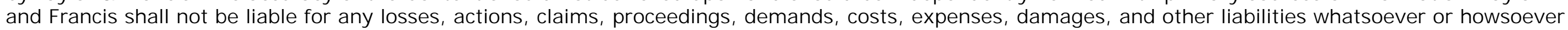
caused arising directly or indirectly in connection with, in relation to or arising out of the use of the Content.

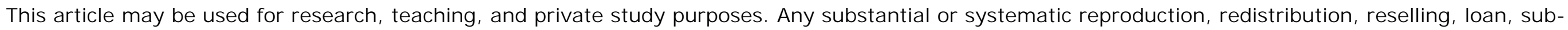
licensing, systematic supply, or distribution in any form to anyone is expressly forbidden. Terms \& Conditions of access and use can be found at http:// www.tandfonline.com/page/terms-and-conditions 


\title{
Designing a framework for dynamic monitoring of ecosystem changes in the Lugu Lake region
}

Hongbing Deng, Shaobo Chen and Rencai Dong

State Key Laboratory of Urban and Regional Ecology, Research Center for Eco-Environmental Sciences, Chinese Academy of Sciences, Beijing, China

Key words: Lugu Lake, dynamic monitoring of ecosystem changes (DMEC), remote sensing, field investigation

\begin{abstract}
SUMMARY
It is important and necessary for sustainable management of regional ecosystems to establish a framework for dynamic monitoring of ecosystem change (DMEC). For sustainable ecosystem management of the Lugu Lake region, the key issues addressed in DMEC are monitoring range, principles, intervals, site and indices, which can be used to create a framework for long-term DMEC for a region. This paper puts forward a new method to combine remote sensing with field investigations to achieve accurate and appropriate changes in a regional ecosystem. Because regional ecosystem change is closely related to local inhabitants, the authors also consider the participation of these people. Finally, the use of DMEC to provide a framework for decision-making and sustainable management of a regional ecosystem is described.
\end{abstract}

\section{INTRODUCTION}

Human activities have caused extensive and rapid changes to natural ecosystems. Because these changes directly influence human welfare, research on regional ecosystem change has received much attention, and is an important aspect of global change research. The simplest method to monitor ecosystem change is to collect long-term data on structure, function and biodiversity of the ecosystem, so as to understand trends and drivers that can be used for decision-making in ecological protection, resource utilisation and environmental management (Yu et al. 2002). Regional ecosystem monitoring needs to encompass long-term patterns and processes of each type of ecosystem within the region at different

spatial and temporal scales. Therefore, an accurate, low cost scientific system for monitoring and an effective operational framework are essential for dynamic long-term monitoring of regional ecosystem changes.

Several global change networks for ecosystem research have been developed, and methods for ecosystem monitoring are constantly improving. Among these networks are the Environmental Change Network (ECN) in the UK, the Long-Term Ecological Research program (LTER) in the USA, the Terrestrial Ecosystem Research Network in Germany, the International Long-Term Ecological Research (ILTER) and Global Terrestrial

Correspondence: Rencai Dong, State Key Laboratory of Urban and Regional Ecology, Research Center for Eco-Environmental Sciences, Chinese Academy of Sciences,18 Shuangqing Road, Haidian District, Beijing 100085, China. Email: dongrencai@rcees.ac.cn 
Observation System (GTOS) projects. In China, the Chinese Ecosystem Research Network (CERN 2006) was established in 1988, and includes 36 field stations in various ecosystems to monitor agriculture, forestry, grassland and water systems, five interdisciplinary centres and a synthesis centre. All the CERN stations engage in monitoring, research, experiments and demonstration projects, while the interdisciplinary centres are responsible for calibration of monitoring instruments and data quality control. The synthesis centre functions as a data exchange engine for interdisciplinary research. Through its long-term monitoring, research, experimentation, demonstration and extension, CERN has served as an important facility to control and understand desertification, soil erosion, salinisation and eutrophication in China Most of the fixed stations are sponsored by special funds and run by local professional departments, their distribution is scattered and their range limited. Hence, the existing stations cannot meet the requirements for monitoring every regional hotspot ecosystem. In hotspot regions, it is necessary to establish independent ecosystem monitoring systems where the priority is management and research for decision-making by the local ecosystem management authority (Fisher and Kus 2003).

The Lugu Lake region in Yunnan Province is a hotspot natural landscape around a plateau lake where the Mosuo people have lived for centuries, and their characteristic matriarchal culture is well preserved. Lugu Lake region is well-known for it natural ecosystems and cultural heritage (Guo et al. 1996; Zhou 2001; Ye 2006). However, in recent years, along with rapid development of society and the economy, especially development of a tourism industry, the natural environment and cultura heritage in this region have been subject to great human disturbance. Because of the natural landscape of the lake and the Mosuo people's unique matriachal culture, Lugu Lake region has become one of the most important areas requiring ecosystem conservation and protection, and extensive concerns over the long-term survival of the ecosystem and its people have been raised by ecologists, economists and social scientists.

To guarantee sustainable management of this regional ecosystem, it is necessary to establish a suitable framework for dynamic monitoring of ecosystem change (DMEC). Building DMEC in the Lugu Lake region will provide a service for decision-makers for sustainable management of the ecosystem in this special region. The key issues for DMEC in the Lugu Lake region are the monitoring range, intervals, extent of the site and developing an index to establish a framework for long-term DMEC. This is the focus of the present paper and includes step-by-step analysis of the procedures developed.

\section{FRAMEWORK FOR DMEC IN THE \\ LUGU LAKE REGION}

\section{Defining the monitoring range}

Lugu Lake region includes the whole of the lake around which most Mosuo people live, the surrounding topography, landscape, endemicity and socio-economic characteristics. In terms of geobiology, ecosystem integrity and landscape ecology, the region can be zoned into three parts: Yongning River watershed $\left(1609 \mathrm{~km}^{2}\right)$, Lugu Lake scenic area $\left(508 \mathrm{~km}^{2}\right)$ and Lugu Lake watershed $\left(247 \mathrm{~km}^{2}\right)$ (Figure 1). The Lugu Lake scenic area was planned by the local government and is the main area under intense human disturbance and, therefore, the main monitoring area. The area outwith Lugu Lake scenic area has less human disturbance, and information on ecosystem changes in this area are useful for comparison. The whole monitoring area covers $60 \times 60 \mathrm{~km}$, centred on Lugu Lake (Figure 1) Because Lugu Lake watershed is in the lower reaches of the Yongning River, and is affected directly by ecosystem changes in the upper reaches of the river, the monitoring area should include the whole watershed of Lugu Lake and Yongning River. In this research, the watershed boundaries of Lugu Lake and Yongning River were generated from a digital elevation model (DEM) with a scale of 1:250000 using Arc View 3.1 and a SWAT model (Bärlund et al. 2006)

\section{Establishing monitoring principles and intervals}

The aim of DMEC in Lugu Lake region is to detect ecosystem changes and to support decision making for sustainable ecosystem management. Some general principles are required:

1. As Lugu Lake is the home of the Mosuo people, DMEC is combined with ethnologic, social and economic investigations. 


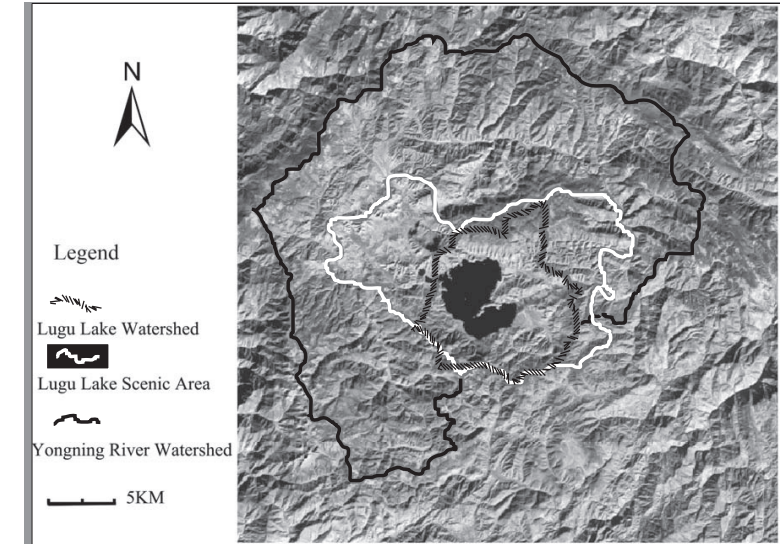

Figure 1 Sketch map of whole monitoring area

2. DMEC includes remote sensing data and field investigations.

3. Permanent fixed sites and temporary monitoring sites were established, and differen sites monitor different aspects over different time periods.

4. The cost and feasibility of monitoring were considered.

5. Participation of the local people was essential.

For biological and soil factors of DMEC, the monitoring interval is 5 years. As water environment factors are sensitive to environmental change, these are monitored every month. The monitoring frequency of Lugu Lake watershed and the scenic area is higher than that outwith these areas. The water shed is monitored once per year, and the scenic area every 5 years. The period for remote sensing data acquisition is 5 years.

\section{Selecting monitoring sites}

Selection of a sampling strategy at sites affects monitoring results, especially for biodiversity monitoring (Chiarucci et al. 2001). Accordingly, field sites include permanent and temporary sites. The permanent terrestrial sites were determined according to geographic coordinates and spatial distribution of the ecosystem, and 16 permanent terrestrial sites, one site per $15 \times 15 \mathrm{~km}$ area, were established within the total monitoring range of $60 \times 60 \mathrm{~km}$ Among the 16 permanent terrestrial sites, three sites are in the Lugu Lake watershed, two outwith the watershed but in the scenic area, seven outwith the scenic area but in Yongning River watershed, and four in the monitoring area outside the Yongning River watershed. The ecosystem types of the 16 permanent terrestrial sites are grassland, forest and farmland, and the corresponding ecosystem type and position in the $15 \times 15 \mathrm{~km}$ area were determined by representative sampling. There are four grassland sites, four farmland sites and six forest sites. For aquatic ecosystems, including wetland, river and lake, there are ten permanent sites, three for wetland ecosystems, three for the river ecosystem (upstream in the forest, midstream in farmland, and downstream in the inhabited area), and four for Lugu Lake (including the inlet and outlet of the lake).

Investigations of inhabitants include social, economic and cultural studies by interviewing local people. Representative local families were selected for long-term monitoring and differences in economic incomes between different villages are considered.

\section{Monitoring indices and data collection}

Monitoring of ecosystem changes depends on objective observation and measurement, not subjective evaluation. Indices of ecosystem monitoring are items and parameters that characterise the situation and any changes. With respect to the regional ecosystem in Lugu Lake, monitoring involves methods to measure ecosystem services, structure and sustainability. Synthetic observation is applied to ecosystems which have commonalities, and special monitoring is used for unique ecosystems. For example, ecosystems such as farmland, forest and pasture have the same essential elements of biology, soil and atmosphere and can be sampled and monitored together. At the same time, individual assessment needs to be carried out for unique ecosystems. For the farmland ecosystem, it is necessary to investigate crops, fertiliser use, and plant nutrient content. For the forest and lake ecosystems, the volume of timber and structure of the forest stand and other essential characteristics were investigated and monitored.

The index selected should include unambiguous ecological data that are easy to measure, repeatable and highly sensitive. For sharing data and cooperative research between regions, index selection must reach international and national standards. Table 1 shows the monitoring indices and corresponding manipulation of data for the region. 


\section{Work flow for ecosystem monitoring}

A precondition for monitoring the regional ecosystem is to build a baseline database for background information. In this study, the data from satellite images in 1990 constituted baseline and background information. Thereafter, dynamic data on farmland, forest, pasture and human environments were captured through periodic remote sensing images, and the indices from ground investigations and mechanisms driving ecosystem changes were compared and analysed. Together, this information allows assessment of benefits and losses that can be used to develop a strategy for ecosystem management that will provide information for decision making and sustainable management of the ecosystem. The work flow involved in monitoring is shown in Figure 2.

\section{DISCUSSION}

\section{Combining remote sensing and field} observations

By combining remote sensing and field observations, representative and comparative data on the status quo and trends in the ecological environment can be obtained that provide scientific

Table 1 Monitoring indices and data collection for the Lugu Lake region

\begin{tabular}{|c|c|c|c|}
\hline Objectives & Items & Index & Data \\
\hline \multirow[t]{7}{*}{$\begin{array}{l}\text { Integrated ecosystem } \\
\text { monitoring }\end{array}$} & Ecosystem structure & $\begin{array}{l}\text { Variation in area; } \\
\text { Changes to ecosystem }\end{array}$ & $\begin{array}{l}\text { Remote sensing; Establishing } \\
\text { ecosystem type }\end{array}$ \\
\hline & Biodiversity & $\begin{array}{l}\text { Landscape and ecosystem } \\
\text { diversity }\end{array}$ & $\begin{array}{l}\text { Remote sensing; Calculating } \\
\text { landscape index }\end{array}$ \\
\hline & Landscape pattern & $\begin{array}{l}\text { Fragmentation index; } \\
\text { Connectivity index }\end{array}$ & $\begin{array}{l}\text { Remote sensing; Calculating } \\
\text { landscape index }\end{array}$ \\
\hline & Biology & $\begin{array}{l}\text { Cover; Community; Succession; } \\
\text { Phenology }\end{array}$ & $\begin{array}{l}\text { Investigation of field area; } \\
\text { Remote sensing }\end{array}$ \\
\hline & Soil & $\begin{array}{l}\text { Physical and chemical } \\
\text { characteristics }\end{array}$ & $\begin{array}{l}\text { Investigation of field area based } \\
\text { on CERN }\end{array}$ \\
\hline & Moisture & $\begin{array}{l}\text { Water physical parameters; } \\
\text { Water chemistry }\end{array}$ & $\begin{array}{l}\text { Investigation of field area based } \\
\text { on CERN }\end{array}$ \\
\hline & Atmosphere & $\begin{array}{l}\text { Criterion index from } \\
\text { automated meteorology }\end{array}$ & $\begin{array}{l}\text { Investigation of field area based } \\
\text { on CERN }\end{array}$ \\
\hline \multirow[t]{3}{*}{$\begin{array}{l}\text { Monitoring specific } \\
\text { ecosystems }\end{array}$} & Farmland ecosystem & Crops; Fertiliser; Plant features & $\begin{array}{l}\text { Investigation of field area based } \\
\text { on CERN }\end{array}$ \\
\hline & Forest ecosystem & $\begin{array}{l}\text { Volume of timber; } \\
\text { Forest age structure }\end{array}$ & $\begin{array}{l}\text { Field and remote sensing } \\
\text { investigations based on CERN }\end{array}$ \\
\hline & Lake ecosystem & Bottom characteristics of lake & $\begin{array}{l}\text { Investigation of field area based } \\
\text { on CERN }\end{array}$ \\
\hline \multirow[t]{4}{*}{ Human systems } & Marriage & $\begin{array}{l}\text { Percentage of Axia } \\
\text { relationships; Intermarriage } \\
\text { with other ethnic groups }\end{array}$ & Field investigation of households \\
\hline & Economics & $\begin{array}{l}\text { Income per capita; Energy } \\
\text { consumption; Tourism income }\end{array}$ & Field investigation of households \\
\hline & Welfare & Education; Medical facilities & Field investigation of households \\
\hline & Ownership of land & $\begin{array}{l}\text { Individual, collective and } \\
\text { state-owned land }\end{array}$ & Field investigation of households \\
\hline
\end{tabular}




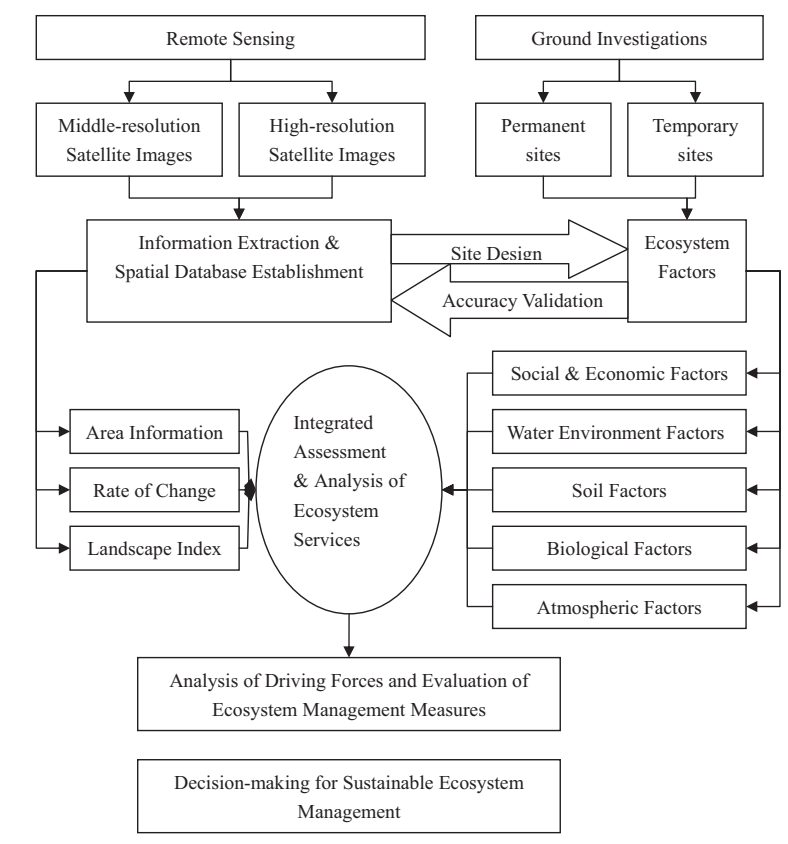

Figure 2 Work flow for ecosystem monitoring

support for better use of natural resources and for implementing strategies of sustainable development. Based on the integration of information from regular remote sensing and quality information from field observations, we can develop a model of ecosystem services to evaluate trends in the Lugu Lake ecosystem. Only such dynamic monitoring of ecosystems will support the final aim of estimating and evaluating regional ecosystem services.

\section{Local participation in regional ecosystem monitoring}

The participation of local people is very important and necessary to obtain data for many of the indices. Local people know the local ecosystem and are aware of changes in regional characteristics of the ecosystem. The Mosuo people were unable to identify all the species in the monitoring area, but their long-term experience allowed them to recogise the rare species and gradual changes in the biome. More importantly, local people could identify exotic and recently introduced species.
The Mosuo not only know the practical value of the natural ecosystem and its biological resources, such as livestock, but have the capacity to reinforce the local ecology and environment if they are provided with government investment (Koto et al. 2004). Hence, local people are an essential component in monitoring dynamic changes and managing sustainable development of ecosystems.

\section{CONCLUSIONS}

In order to guarantee sustainable management of the Lugo Lake ecosystem, it is important and urgent to establish a complete framework for dynamic monitoring. Moreover, in the process of implementation, it is necessary to develop a scientific system consisting of easily measured, highly sensitive, sustainable and comparable indices. At the same time, considering the large scale and periodic features of ecosystem change, the sustainability of monitoring is essential so that the ecosystem management system serves regional sustainable development.

According to results from previous research and our studies and analysis of the Lugu Lake watershed, the combination of the remote sensing and field observations constitutes an efficient method for dynamic monitoring of ecosystem changes in this hotspot of human activity. Furthermore, these methods will improve the current lack of sufficient evenly distributed stations in the monitoring network for national ecosystems. Our results show that, in developing countries, adopting simple and feasible measures to improve ecosystem monitoring and changing human activities is important and necessary.

\section{ACKNOWLEDGEMENTS}

This study was supported by the Chinese Academy of Sciences (KZCX3-SW-438), the National Natural Science Foundation of China (Nos. 70403014; 70325002), and the Ministry of Science and Technology of the People's Republic of China (2005DIB3J002). 


\section{REFERENGES}

Bärlund I, Kirkkala T, Malve $\mathrm{O}$ and Kämäri J. Assessing SWAT model performance in the evaluation of management actions for the implementation of the Water Framework Directive in a Finnish catchment. Environmental Modelling $\mathcal{E}$ Software 2006:1-6

CERN. Long-term dynamic monitoring database of Chinese ecosystems. http://www.cern.ac.cn/; 2006

Chiarucci A, Dominicis V, Wilson JB. Structure and floristic diversity in permanent monitoring plots in forest ecosystems of Tuscany. Forest Ecology and Management 2001;141:201-10

Fisher R and Kus B. Development of a Comprehensive Ecological Monitoring Strategy in Support of the Coastal Sage Scrub NCCP Program in Southern California and Analysis of the Existing Monitoring Efforts. http:// www.werc.usgs.gov; 2003

Guo LX, Wan Y, Lin JP, et al. The protective region's construction on natural-social-ecological system of Lugu Lake. Yunnan Geographic Environment Research 1996;8(1):37-49

Koto B, Zo L, Razafiarison S, Andriantsarafara, et al. Ecological Monitoring Plan. Operational Planning Workshop for Ecological Conservation Monitoring, Antananarivo, 22-24 June. http://portals. conservation.org/marine/codebase/handlers; 2004

Ye W. Value Dimensions of Tourism Planning: Ethnic Cultures and Sustainable Development of Tourism. Beijing: China Environmental Sciences Press; 2006

Yu Gui-rui, Xie Gao-di, Yu Zhen-liang, et al. Important ecological topics on regional scale ecosystem management in China. Chinese Journal of Applied Ecology 2002;13(7):885-91

Zhou HS. A region of no father and no husband. Beijing: Guangming Daily Press; 2001 